\title{
Radiation Effects in Nuclear Waste Materials
}

(Project Number: 73750)

\section{Principal Investigator}

William J. Weber

Pacific Northwest National Laboratory

P.O. Box 999, MSIN K8-93

Richland, WA 99352

509-376-3644 (phone)

509-376-5106 (fax)

bill.weber@pnl.gov

Co-Investigators

Lumin Wang

Nuclear Engineering \& Radiological

Sciences

The University of Michigan

2355 Bonisteel Boulevard

Ann Arbor, MI 48109-2104

734-647-8530 (phone)

lmwang@umich.edu

Nancy J. Hess

Pacific Northwest National Laboratory

P.O. Box 999, MSIN P7-50

Richland, WA 99352

509-376-9808 (phone)

509-372-1632 (fax)

nancy.hess@pnl.gov
Jonathan P. Icenhower

Pacific Northwest National Laboratory P.O. Box 999, MSIN K6-81

Richland, WA 99352

509-372-0078 (phone)

509-376-2210 (fax)

jonathan.icenhower@pnl.gov

Suntharampillai (Theva) Thevuthasan Pacific Northwest National Laboratory P.O. Box 999, MSIN K8-93

Richland, WA 99352

509-376-1375 (phone)

509-376-5106 (fax)

theva@pnl.gov 


\section{Research Objective}

The objective of this project is to develop a fundamental understanding of radiation effects in glasses and ceramics, as well as the influence of solid-state radiation effects on aqueous dissolution kinetics. This study will provide the underpinning science to develop improved glass and ceramic waste forms for the immobilization and disposition of high-level tank waste, excess plutonium, plutonium residues and scrap, other actinides, and other nuclear waste streams. Furthermore, this study will develop predictive models for the performance of nuclear waste forms and stabilized nuclear materials. The research focuses on the effects of alpha and beta decay on defect production, defect interactions, diffusion, solid-state phase transformations, and dissolution kinetics. Plutonium incorporation, ion-beam irradiation, and electron-beam irradiation are used to simulate the effects of alpha decay and beta decay on relevant glasses and ceramics in experimental studies. Computer simulation methods are used to provide an atomiclevel interpretation of experimental data and continuum-level modeling.

\section{Research Progress and Implications}

This report summarizes progress after 15 months of a 3-year project. The co-investigator at the University of Michigan did not receive funding until September 2001; thus, this report summarizes progress after only 7 months for those activities.

\section{Computer Simulation Efforts}

Computer simulation studies of ionization effects in glasses are continuing to wrap up the studies initiated under our previous EMSP project. Computer simulations of radiation damage processes in ceramics are continuing. An initial collaborative study on threshold displacement processes in zircon has been completed. This study has illustrated for the first time the importance of heterogeneous displacement sequences on damage production processes in complex ceramics. This collaborative effort has expanded to include a group of researchers from the French Atomic Energy Commission (Commissariat a l'Energie Atomique, or CEA).

\section{Alpha-Decay Effects in Glasses and Ceramics}

Because some dissolution measurements were performed on the $\mathrm{Pu}$-doped glasses immediately after preparation in 1982, the same dissolution measurements are being performed on these glasses in their current radiation-damaged state for comparison. In addition, a comprehensive set of dissolution kinetics experiments is in progress on the ${ }^{239} \mathrm{Pu}$-doped glass (lightly damaged) and the ${ }^{238} \mathrm{Pu}$-doped glass (highly damaged) using the single-pass flow-through (SPFT) test method to measure the forward reaction rate of these glasses. All experiments are being run at $90^{\circ} \mathrm{C}$ in 
$\mathrm{pH}=2$ solutions using the SPFT apparatus developed at Pacific Northwest National Laboratory (PNNL). These tests still are ongoing, and data will not be available until later this year.

\section{Simulation of Radiation Effects Using Ion Beams}

Pyrochlores of the type $\mathrm{Gd}_{2}\left(\mathrm{Ti}_{1-\mathrm{x}} \mathrm{Zr}_{\mathrm{x}}\right)_{2} \mathrm{O}_{7}$ exhibit an increase in resistance to radiation-induced amorphization with increasing $\mathrm{x}$ ( $\mathrm{Zr}$ content). Detailed studies of the effects of composition and radiation damage on the dissolution behavior in this pyrochlore system are now in progress. The stability of the $\mathrm{A}_{2} \mathrm{~B}_{2} \mathrm{O}_{7}$ pyrochlores is governed by the ionic radii ratio of the $\mathrm{A}$ and $\mathrm{B}$ site cations $\left(\mathrm{r}_{\mathrm{A}} / \mathrm{r}_{\mathrm{B}}\right)$. In collaboration with other scientists at Lawrence Berkeley National Laboratory (LBNL), a detailed characterization is being performed of $\mathrm{Gd}_{2}\left(\mathrm{Ti}_{1-\mathrm{x}} \mathrm{Zr}_{\mathrm{x}}\right)_{2} \mathrm{O}_{7}$ pyrochlores, with $\mathrm{x}=0,0.25,0.5,0.75$, and 1.0 , whose ionic radii ratios span the complete pyrochlore stability field from $r_{A} / r_{B}=1.74(x=0)$ to $r_{A} / r_{B}=1.46(x=1)$, by near-edge $x$-ray absorption fine-structure spectroscopy at the titanium $\mathrm{L}$ and oxygen $\mathrm{K}$-edges. The results indicate that $\mathrm{Ti}$ is in a distorted octahedral environment $\left(\right.$ like $\left.\mathrm{TiO}_{2}\right)$ for $\mathrm{x}=0$, and the deviation from the regular octahedral symmetry decreases for increasing $x$. For $x \geq 0.75$, the Ti occupies a regular octahedral site, as in $\mathrm{SrTiO}_{3}$. Likewise, the results support that $\mathrm{Zr}$ systematically replaces $\mathrm{Ti}$ with increasing $\mathrm{x}$ and, furthermore, the coordination number of $\mathrm{Zr}$ increases with increasing $\mathrm{x}$.

To assess the aqueous dissolution behavior of the $\mathrm{Gd}_{2}\left(\mathrm{Ti}_{1-\mathrm{x}} \mathrm{Zr}_{\mathrm{x}}\right)_{2} \mathrm{O}_{7}$ system, SPFT testing has been conducted on monolithic specimens. As in the case of the Pu-doped glasses, the tests were run at $90^{\circ} \mathrm{C}$ in $\mathrm{pH}=2$ solutions using the SPFT apparatus developed at PNNL. In this system, the goal is to quantify the difference in dissolution rate as a function of composition. As noted above, the compositional variation of interest is the exchange of $\mathrm{Zr}^{4+}$ for $\mathrm{Ti}^{4+}$, which is known to induce disorder in the materials. At the extreme end of the exchange scale, pure $\mathrm{Gd}_{2} \mathrm{Zr}_{2} \mathrm{O}_{7}$ is manifested as the disordered fluorite structure, rather than the pyrochlore structure, due to the processing procedures, because pyrochlore requires long-term annealing below the orderdisorder transformation. Fully ordered samples with the pyrochlore structure across the composition also are being prepared for testing. Preliminary data for the as-processed samples show that, as the extent of $\mathrm{Zr}^{4+}$ exchange for $\mathrm{Ti}^{4+}$ increases, the dissolution rate decreases. The data indicate that, as $\mathrm{x}$ increases from 0 to 0.75 , the dissolution rate decreases systematically by a factor of about 30. However, in the case of the end-member $\mathrm{Gd}_{2} \mathrm{Zr}_{2} \mathrm{O}_{7}(\mathrm{x}=1.0)$ that crystallizes into the defect fluorite structure during processing, the dissolution rate is higher than that of the pyrochlore $\mathrm{Gd}_{2} \mathrm{Ti}_{2} \mathrm{O}_{7}$ end-member. These results suggest that the disordered fluorite structure has a higher dissolution rate than the ordered pyrochlore state. Preliminary data for the highly ordered pyrochlore specimens indicate the dissolution rates are substantially lower than their asprepared counterparts. The results reveal that the dissolution kinetics of these samples depends on both chemical composition and the degree of disorder within the lattice. Although $\mathrm{Zr}$-rich pyrochlore samples are more disordered than their Ti-rich counterparts, addition of Zr clearly decreases the dissolution rates. 
In collaboration with researchers at the Australian Nuclear Science and Technology Organization (ANSTO), several complex zirconate and titanate pyroclores were irradiated, using an irradiation protocol developed under this project, to produce a stable radiation damage state that simulates the state expected from alpha decay over long time periods at ambient temperature. Glancing angle $\mathrm{x}$-ray diffraction (XRD) confirms that the zirconate compounds are more radiationresistant that the titanate compounds, which readily transform to an amorphous state. The samples are undergoing additional testing by the ANSTO collaborators. Additional samples have been prepared for irradiation as part of this collaboration with the ANSTO group.

Using the same irradiation protocol, samples of $\mathrm{Ca}_{2} \mathrm{Nd}_{8}\left(\mathrm{SiO}_{4}\right)_{6} \mathrm{O}_{2}$ (apatite structure) have been irradiated with 2-MeV Au ions to produce a fully amorphous state to a depth of about $600 \mathrm{~nm}$, which has been confirmed by cross-sectional transmission electron microscopy (TEM). These samples are currently undergoing dissolution testing using the SPFT test method as described above, and detailed characterization of the amorphous state is being performed. Additional studies are planned to investigate the temperature dependence. The results of these studies will be compared to previous results due to alpha-decay damage in samples of this material containing ${ }^{244} \mathrm{Cm}$, which should assist in validation of the irradiation protocol.

Based on the results of systematic experimental studies using short-lived actinides, ion-beam irradiation, and new models of radiation damage processes in ceramics, predictive models of radiation-damage behavior due to alpha decay are emerging. Based on ion-beam data, one of the parameters that can be predicted is the critical temperature, $\mathrm{T}_{\mathrm{c}}$, below which radiation-induced amorphization will occur for any given alpha decay rate (actinide content). This is illustrated in Table 1 for several materials of interest.

Table 1. Critical Temperature, Tc, for Ceramics Under Different Damage Rates

\begin{tabular}{|l|c|c|c|c|c|}
\hline $\begin{array}{c}\text { Irradiation } \\
\text { Conditions }\end{array}$ & $\begin{array}{c}\text { Dose Rate } \\
(\mathbf{d p a} / \mathbf{s})\end{array}$ & $\begin{array}{c}\mathbf{G d}_{2} \mathbf{T i}_{2} \mathbf{O}_{7} \\
(\mathbf{K})\end{array}$ & $\begin{array}{c}\mathbf{Z r S i O}_{4} \\
(\mathbf{K})\end{array}$ & $\begin{array}{c}\mathrm{SrTiO}_{3} \\
(\mathbf{K})\end{array}$ & $\begin{array}{c}\mathrm{CaTiO}_{\mathbf{3}} \\
(\mathbf{K})\end{array}$ \\
\hline Ion Beam & $3.3 \times 10^{-3}$ & 980 & 975 & 395 & 420 \\
\hline $10 \mathrm{wt} \%{ }^{239} \mathrm{Pu}$ & $8.5 \times 10^{-12}$ & 580 & 578 & 234 & 249 \\
\hline
\end{tabular}

\section{Simulation of Radiation Effects Using Electron Beams}

We attempted to assess the effects of beta decay using a gamma irradiation facility under our previous project; however, the original 3-year time period proved insufficient to achieve the necessary dose levels. At the end of the project period, sample doses equivalent to only 25 years of storage were achieved in the gamma irradiation facility. Because of the interruption of funding, the irradiation facility no longer is available, and these experiments have been 
terminated The only method now available to evaluate the effects of beta decay on the performance of nuclear waste glasses is electron-beam irradiation. This requires establishing a suitable and reliable radiation protocol for glasses, similar to that developed for radiationinduced amorphization in ceramics. The work being carried out at the University of Michigan under this project is focused on understanding radiation-damage processes in complex glasses and developing the necessary protocols to perform accelerated radiation effects testing.

Initial studies at the University of Michigan have focused on a series of Na-borosilicate (NBS) glasses developed under our previous project. The composition of these glasses is given in Table 2.

Table 2. Chemical Composition of NBS Glasses

\begin{tabular}{|l|c|c|c|}
\hline \multicolumn{1}{|c|}{ Oxide } & NBS-1 (wt\%) & NBS-2 (wt\%) & NBS-3 (wt\%) \\
\hline $\mathrm{B}_{2} \mathrm{O}_{3}$ & 17.72 & 17.78 & 17.86 \\
\hline $\mathrm{Fe}_{2} \mathrm{O}_{3}$ & 0 & 4.99 & 0 \\
\hline $\mathrm{FeO}$ & 0 & 0 & 4.61 \\
\hline $\mathrm{Na}_{2} \mathrm{O}$ & 16.67 & 15.83 & 15.90 \\
\hline $\mathrm{SiO}_{2}$ & 64.61 & 61.39 & 61.63 \\
\hline
\end{tabular}

The preliminary results, performed by a new postdoctoral fellow at the University of Michigan, indicate a significant mobility of $\mathrm{Na}$ under irradiation with $200-\mathrm{keV}$ electrons at room temperature, which is consistent with many previous observations. There is a rapid decrease in the $\mathrm{Na}$ concentration in the area under irradiation, and the addition of the $\mathrm{FeO}$ or $\mathrm{Fe}_{2} \mathrm{O}_{3}$ to the glass appears to hinder the mobility of the Na. Ongoing studies will investigate the effects of dose rate on this behavior and on the oxidation state of the Fe.

\section{Planned Activities}

\section{Computer Simulations}

The multi-institutional collaborative efforts on damage production processes and stable damage states in complex ceramics will continue, and improved interatomic potentials will be used in molecular dynamic simulations of high-energy collision processes in an effort to understand the nature of radiation resistance in some of these complex ceramics.

The studies of electronic excitations in glasses will be brought to closure. 


\section{Alpha-Decay Effects in Glasses and Ceramics}

It is critical to determine the local changes in structure of the boron in the three Pu-doped glasses that have been previously studied under this project, as this information may be important to understanding the changes in dissolution kinetics. These measurements will be carried out using LBNL's user facility, the Advanced Light Source. The presence of any molecular oxygen that may have been produced in these glasses because of radiation-induced decomposition will be probed using Raman and infrared photoluminescence.

The dissolution tests on the Pu-doped glasses are expected to be completed by the end of the year. An annealing study of the amorphous ${ }^{238} \mathrm{Pu}$-zircon will be carried out at 600,700 , and $800^{\circ} \mathrm{C}$, and $\mathrm{x}$-ray absorption spectroscopy (XAS) measurements (as used under our previous EMSP project) will be performed to understand the early stages of annealing. This recovery process is important to developing and validating long-term predictive models. In addition, Raman spectroscopy will be used to measure the decrease in width of the antisymmetric stretching vibrational band of the $\mathrm{SiO}_{4}$ tetrahedra in the Pu-zircons as a function of annealing temperature.

After these tests are completed, this project will cease all work on actinide-containing materials. Project funding will support related waste disposal and laboratory clean-up efforts.

\section{Electron and Ion Irradiation Studies}

The University of Michigan will continue to lead studies on using electron beams and light-ion $\left(\mathrm{H}^{+}, \mathrm{He}^{+}\right)$beams to study the effects of ionization (from beta and alpha decay) on the structure and stability of complex glasses. Heavy-ion irradiation also will be used to simulate the radiation effects induced by alpha-recoil particles. In situ TEM study during the ion-beam irradiation will be performed using the IVEM-Tandem facility at Argonne National Laboratory. More detailed analysis on ionizing radiation effects in these glasses will be performed with more advanced TEM techniques including energy dispersive spectrometer (EDS) elemental mapping and electron energy loss spectroscopy (EELS), as well as energy filtered TEM and electron diffraction. The elemental mapping should reveal any radiation-induced chemical segregation, and energy-filtered electron diffraction may reveal any small change in the radial distribution function (local atomic arrangements) in the irradiated area.

Ion-irradiation experiments at PNNL will continue to employ heavy ions in studies of irradiation effects in ceramics to further validate irradiation protocols that simulate alpha-decay behavior in ceramics, such as the continuing work on the apatite and proposed work on zirconolite. In addition, the effects of radiation damage on the dissolution behavior of the $\mathrm{Gd}_{2}\left(\mathrm{Ti}_{1-\mathrm{x}} \mathrm{Zr}_{\mathrm{x}}\right)_{2} \mathrm{O}_{7}$ system will be completed over the next year. Small-angle XRD and cross-sectional TEM will be performed on these samples. These studies will provide important data on ceramics that are 
relevant to predicting the performance of ceramics for special waste streams and nuclear materials, such as the pyrochlores and silicotitanates.

\section{Information Access}

Weber WJ. 2000. Radiation Effects in Nuclear Waste Materials. Final Report, EMSP Project Number 54672, (http://emsp.em.doe.gov/products.htm).

Begg BD, NJ Hess, WJ Weber, R Devanathan, JP Icenhower, S Thevuthasan, and BP McGrail. 2001. Heavy-Ion Irradiation Effects on Structures and Acid Dissolution of Pyrochlores. Journal of Nuclear Materials 288(2-3):208-216.

Zhao D, L Li, WJ Weber, and RC Ewing. 2001. Gadolinium Borosilicate Glass-Bonded Gd-Silicate Apatite: A Glass-Ceramic Nuclear Waste Form for Actinides. In Scientific Basis for Nuclear Waste Management XXIV, eds. KP Hart and GR Lumpkin, Mater. Res. Soc. Symp. Proc. 663, pp. 199-206. Materials Research Society, Warrendale, Pennsylvania.

Song J, LR Corrales, G Kresse, and H Jónsson. 2001. Migration of Oxygen Vacancies in $\alpha-$ Quartz: The Effects of Excitons and Electron Holes. Physical Review B 64:134102.

Park B, WJ Weber, and LR Corrales. 2001. Molecular Dynamics Simulation Study of Threshold Displacements and Defect Formation in Zircon. Physical Review B 64:174108, 1-16.

Hess NJ, BD Begg, SD Conradson, DE McCready, PL Gassman, and WJ Weber. 2002. Spectroscopic Investigations of the Structural Phase Transitions in $\mathrm{Gd}_{2}\left(\mathrm{Ti}_{1-\mathrm{y}} \mathrm{Zr}_{\mathrm{y}}\right)_{2} \mathrm{O}_{7}$ Pyrochlores. J. Phys. Chem. B 106:4663-4677.

Stewart MWA, BD Begg, ER Vance, K Finnie, H Li, GR Lumpkin, KL Smith, WJ Weber, and $\mathrm{S}$ Thevuthasan. 2002. The Replacement of Titanium by Zirconium in Ceramics for Plutonium Immobilization. In Scientific Basis for Nuclear Waste Management XXV, eds. BP McGrail and GA Cragnolino, Mater. Res. Soc. Symp. Proc.713, JJ 2.5, pp. 1-8. Materials Research Society, Warrendale, Pennsylvania.

Weber WJ and RC Ewing. 2002. Radiation Effects in Crystalline Oxide Host Phases for the Immobilization of Actinides. In Scientific Basis for Nuclear Waste Management XXV, eds. BP McGrail and GA Cragnolino, Mater. Res. Soc. Symp. Proc. 713, JJ3.1, pp. 1-12, Materials Research Society, Warrendale, Pennsylvania. 
Icenhower JP, BP McGrail, WJ Weber, BD Begg, NJ Hess, EA Rodriguez, JL Steele, CF Brown, and MJ O'Hara. 2002. Dissolution of $\mathrm{A}_{2} \mathrm{Ti}_{2} \mathrm{O}_{7}\left(\mathrm{~A}=\mathrm{Y}^{3+}, \mathrm{Gd}^{3+}\right.$, or $\left.\mathrm{Lu}^{3+}\right)$ Pyrochlore by Experiment at $\mathrm{pH}=2, \mathrm{~T}=90^{\circ} \mathrm{C}$ : Evidence for Solubility Control Using a Linear Free Energy Model. In Scientific Basis for Nuclear Waste Management XXV, eds. BP McGrail and GA Cragnolino, Mater. Res. Soc. Symp. Proc. 713, JJ6.2, pp. 1-7. Materials Research Society, Warrendale, Pennsylvania.

William J. Weber (http://emslbios.pnl.gov/id/weber wj) 